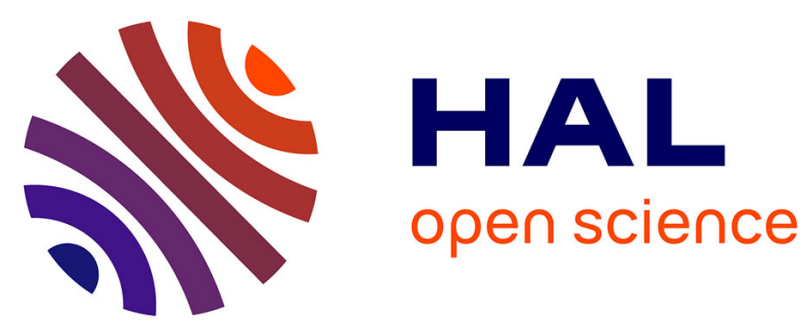

\title{
Intraocular pressure in the smallest primate aging model: the gray mouse lemur
}

\author{
Marko Dubicanac, Marine Joly, Julia Strüve, Ingo Nolte, Nadine
}

Mestre-Francés, Jean-Michel Verdier, Elke Zimmermann

\section{To cite this version:}

Marko Dubicanac, Marine Joly, Julia Strüve, Ingo Nolte, Nadine Mestre-Francés, et al.. Intraocular pressure in the smallest primate aging model: the gray mouse lemur. Veterinary Ophthalmology, 2018, 21 (3), pp.319-327. 10.1111/vop.12434 . hal-01977709

\section{HAL Id: hal-01977709 \\ https://hal.umontpellier.fr/hal-01977709}

Submitted on 3 Apr 2020

HAL is a multi-disciplinary open access archive for the deposit and dissemination of scientific research documents, whether they are published or not. The documents may come from teaching and research institutions in France or abroad, or from public or private research centers.
L'archive ouverte pluridisciplinaire HAL, est destinée au dépôt et à la diffusion de documents scientifiques de niveau recherche, publiés ou non, émanant des établissements d'enseignement et de recherche français ou étrangers, des laboratoires publics ou privés. 


\section{Veterinary Ophthalmology $\underline{\mathrm{ACVO}}$}

\section{Intraocular pressure in the smallest primate aging model, the gray mouse lemur}

\begin{tabular}{|r|l|}
\hline Journal: & Veterinary Ophthalmology \\
\hline Manuscript ID & Draft \\
\hline Wiley - Manuscript type: & Original Report \\
\hline Date Submitted by the Author: & n/a \\
\hline Complete List of Authors: & $\begin{array}{l}\text { Dubicanac, Marko; Tierarztliche Hochschule Hannover, Institute of Zoology } \\
\text { Joly, Marine; Centre for Comparative and Evolutionary Psychology, King } \\
\text { Henry Building } \\
\text { Strueve, Julia; Tierarztliche Hochschule Hannover, Small Animal Clinic of } \\
\text { the University of Hanover } \\
\text { Nolte, Ingo; Tierarztliche Hochschule Hannover, Small Animal Clinic of the } \\
\text { University of Hanover } \\
\text { Verdier, Jean-Michel; Université Montpellier 2, Inserm U1198 } \\
\text { Frances-Mestre, Nadine; Université Montpellier 2, Inserm U1198 } \\
\text { Zimmermann, Elke; Tierarztliche Hochschule Hannover, Institute of } \\
\text { Zoology }\end{array}$ \\
\hline Keywords: & $\begin{array}{l}\text { intraocular pressure, tonometer, reference value, mouse lemur, primate, } \\
\text { aging }\end{array}$ \\
\hline
\end{tabular}




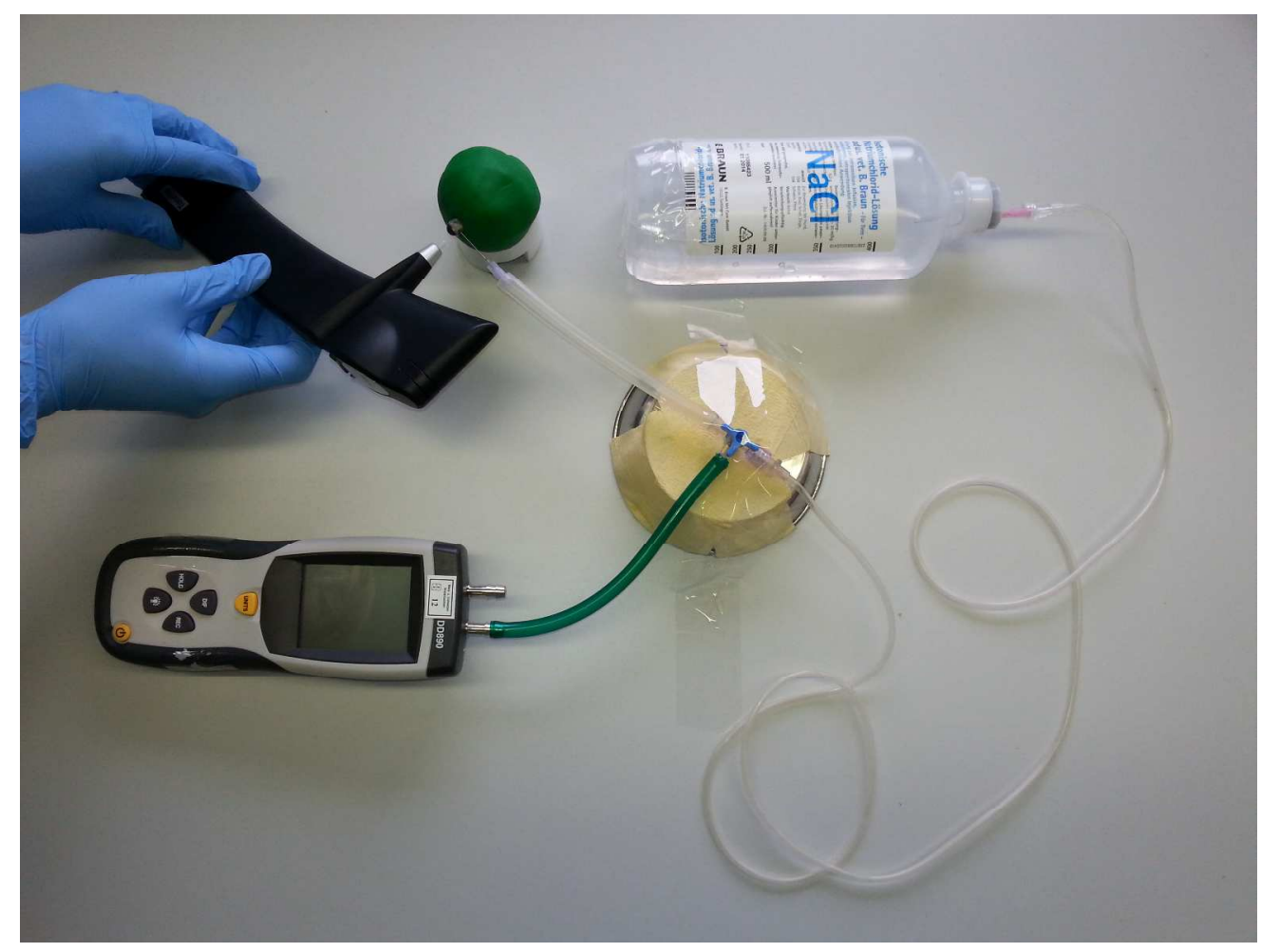

Figure 1. Setup of the manometrical investigation. $1151 \times 863 \mathrm{~mm}(72 \times 72 \mathrm{DPI})$ 


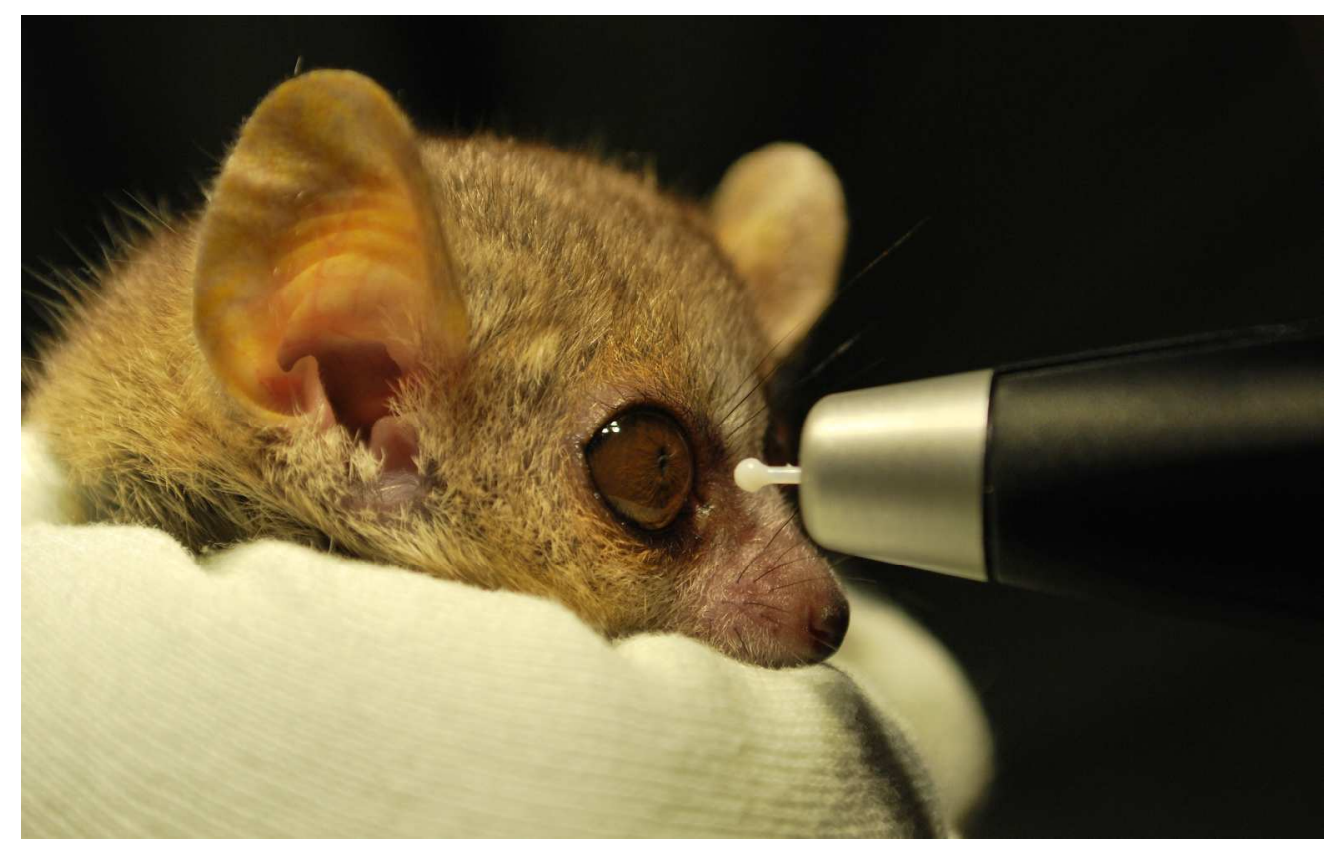

Figure 2. Investigation of a 2 year old mouse lemur with the TonoVet $®$. $283 \times 179 \mathrm{~mm}(300 \times 300 \mathrm{DPI})$ 


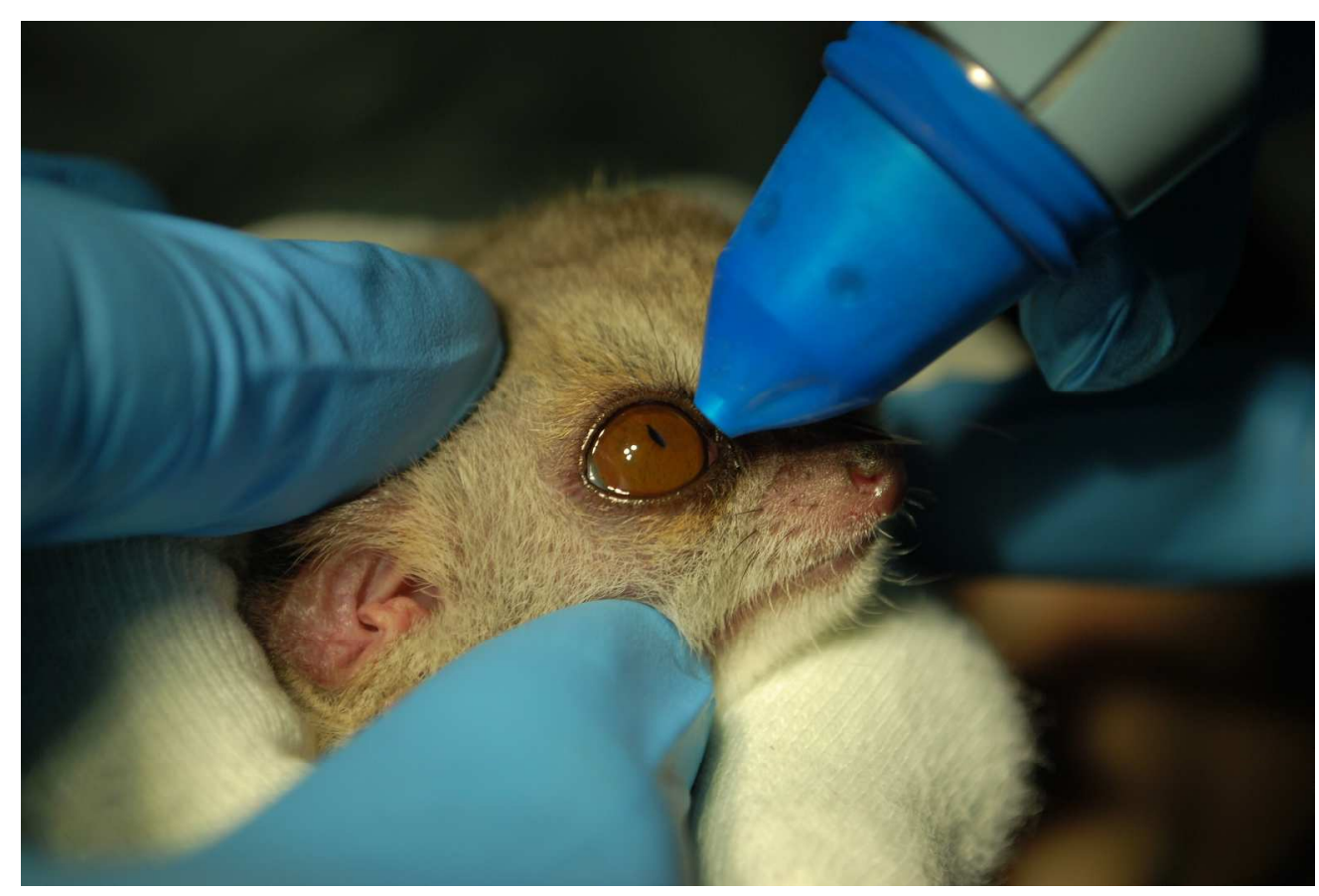

Figure 3. Investigation of a 2 year old mouse lemur with the TonoPen ${ }^{\mathrm{TM}}$ $1024 \times 685 \mathrm{~mm}(96 \times 96 \mathrm{DPI})$ 


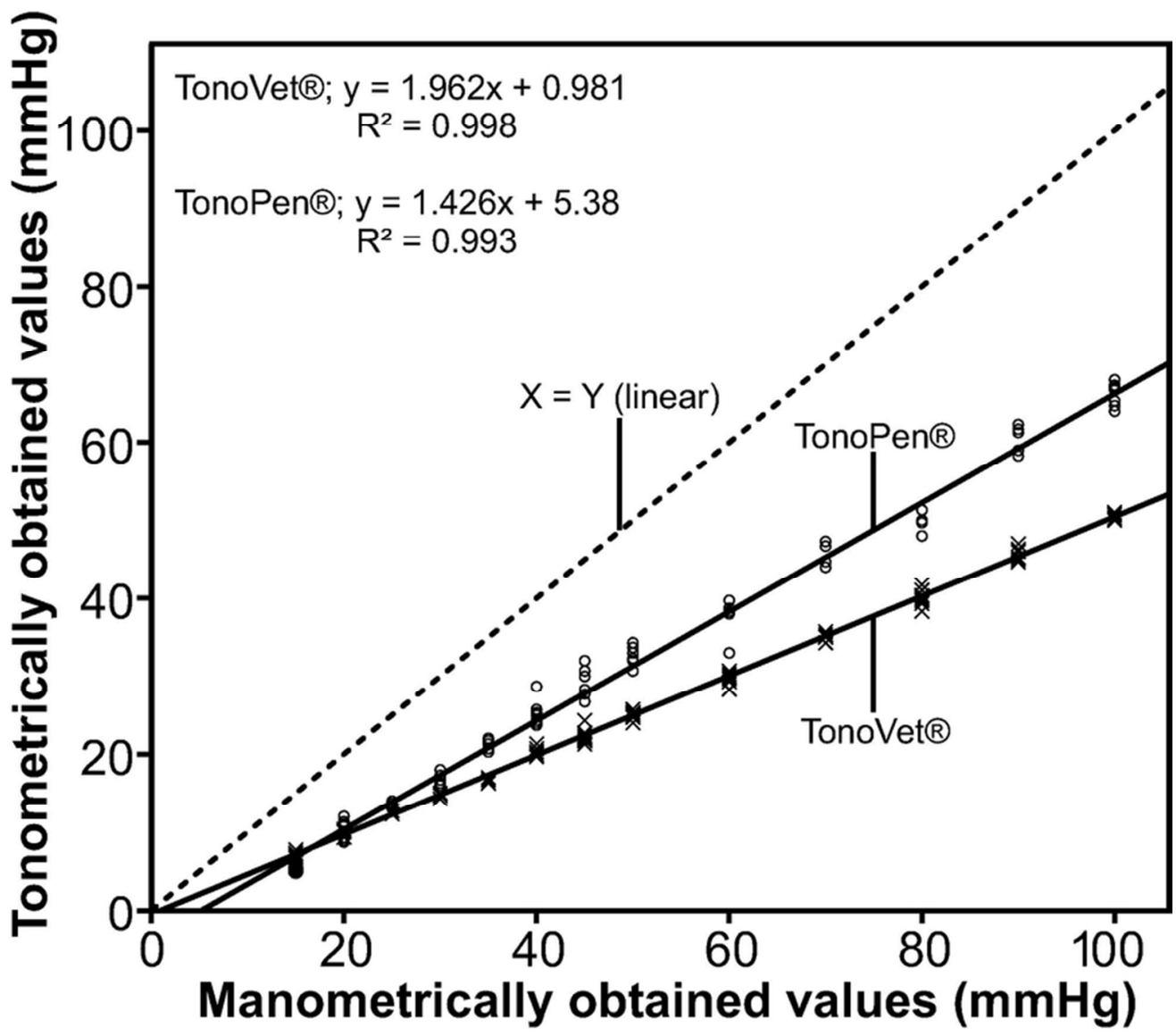

Figure 4. Values measured with the TonoVet ${ }^{\circledR}$ and TonoPen ${ }^{\mathrm{TM}}$ under manometrical control. Manometrically determined IOP for the eight eyes of four animals are represented on the $\mathrm{x}$-axis. TonoVet ${ }^{\circledR}$ and TonoPen ${ }^{\mathrm{TM}}$ values are represented on the $y$-axis. Each dot represents the mean from three measurements per step/per

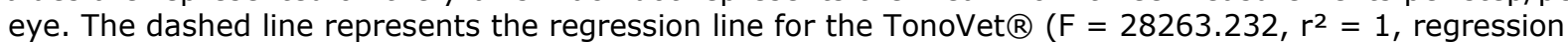
analysis, $\mathrm{p}<0.001)$ and TonoPen ${ }^{\mathrm{TM}}\left(\mathrm{F}=3497.514, \mathrm{r}^{2}=0.997\right.$, regression analysis, $\left.\mathrm{p}<0.001\right)$ measurements. $73 \times 64 \mathrm{~mm}(300 \times 300 \mathrm{DPI})$ 


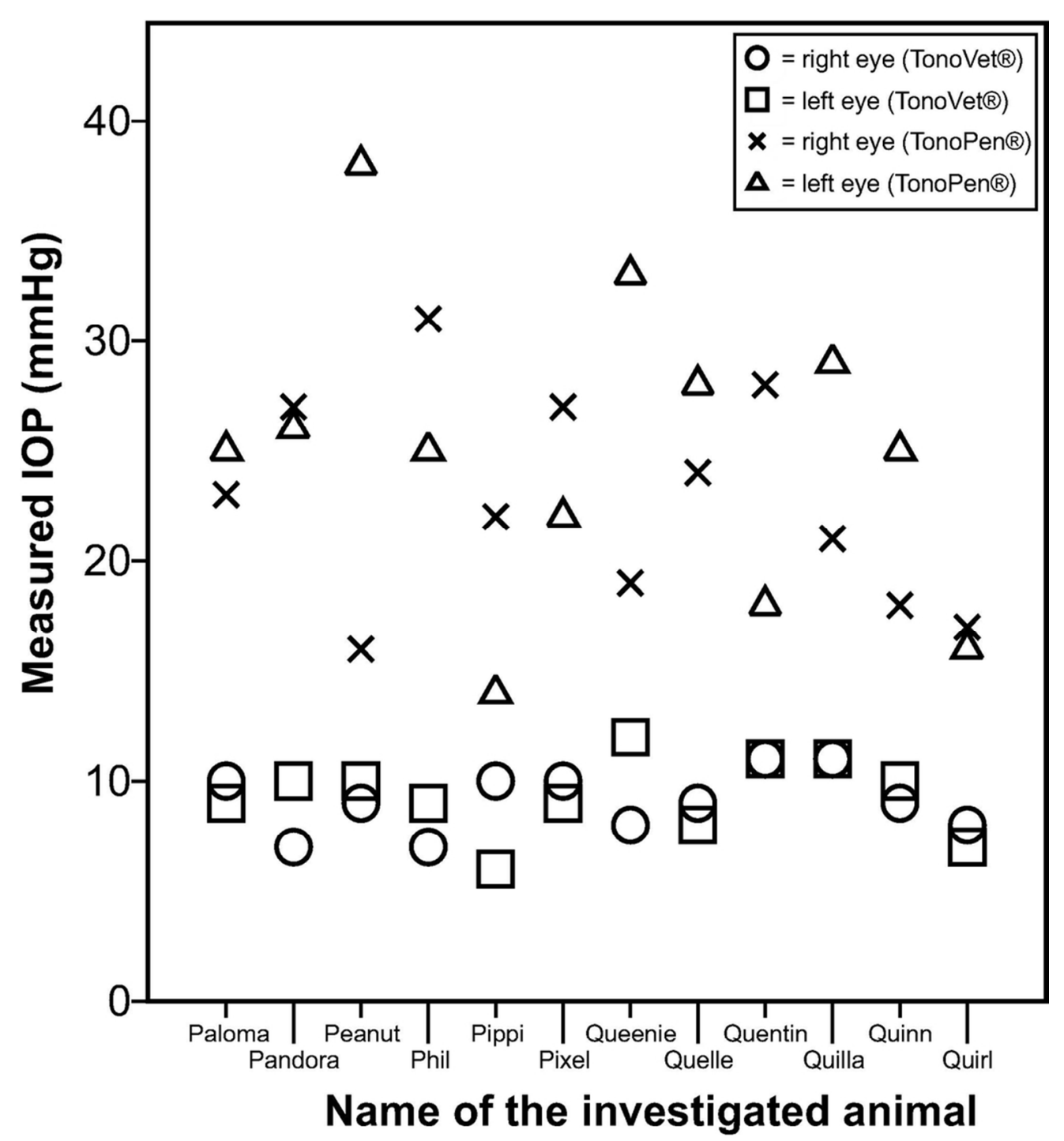

Figure 5. Comparison of the in-vivo measured IOP for the TonoVet $®$ and TonoPen ${ }^{\mathrm{TM}}$ in 12 animals. The results show high variation in measurements for the TonoPen ${ }^{\mathrm{TM}}$ and much more consistent values for the TonoVet $\AA$. E.g. Peanut (TonoPen ${ }^{T M}$ left eye $38 \mathrm{mmHg}$, right eye $16 \mathrm{mmHg}$; TonoVet $\AA$ left eye $10 \mathrm{mmHg}$, right eye $9 \mathrm{mmHg}$ ). For exact values (see Tab. 1). 


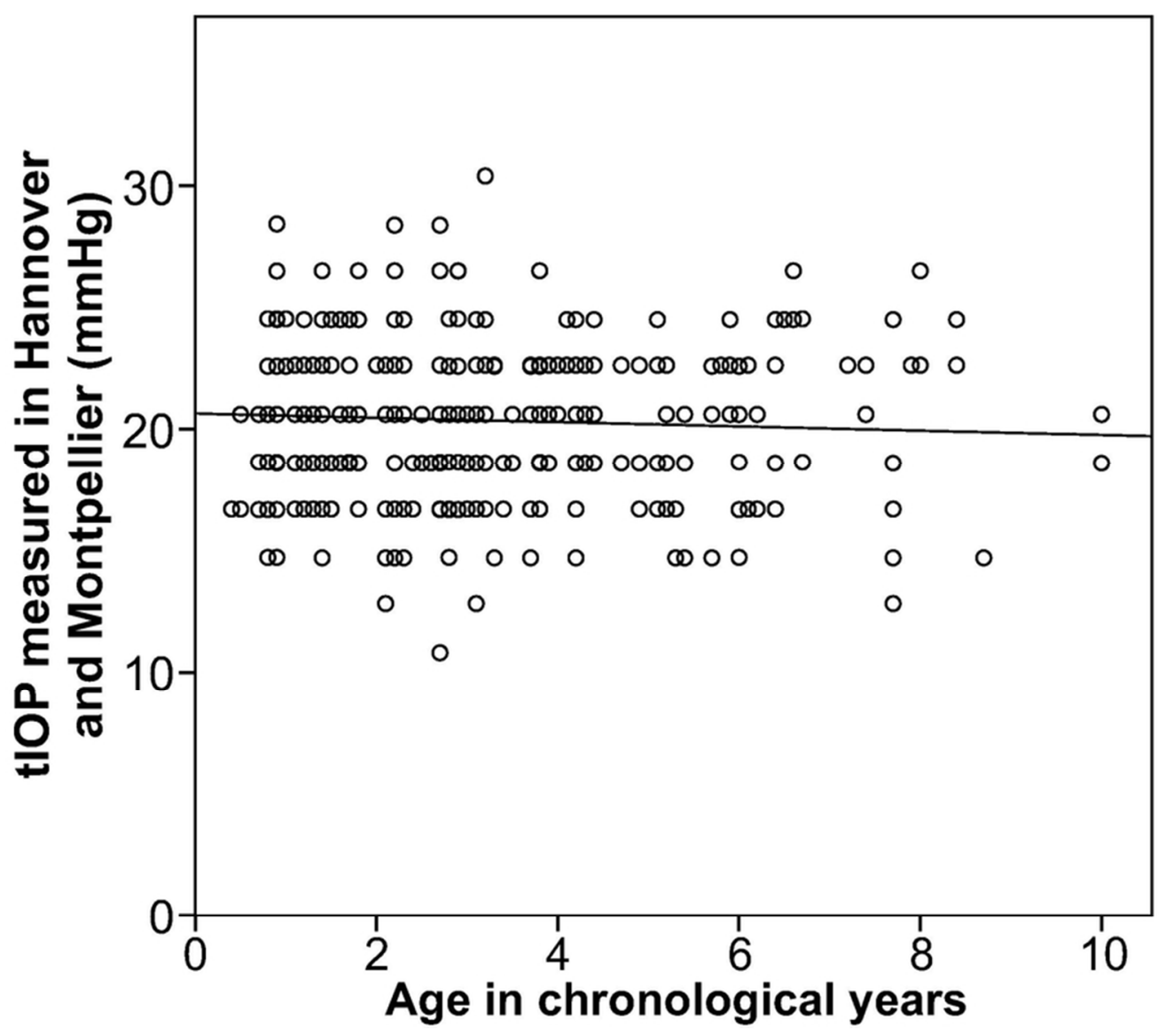

Figure 6. Relation between tIOP values and age in healthy mouse lemur eyes. This scatterplot shows the tIOP values for all measured healthy animals from Hannover and Montpellier $(\mathrm{N}=258)$ on the $y$-axis in relation to age on the $x$-axis. The decrease in IOP is statistically not significant ( $p=0.077, r s=-0.110$ ). 
1 Intraocular pressure in the smallest primate aging model, the gray mouse lemur

2

3 Suggested running title: Intraocular pressure in aging mouse lemurs

5 Marko Dubicanac ${ }^{1}$, Marine Joly ${ }^{1,2}$, Julia Strüve ${ }^{3}$, Ingo Nolte ${ }^{3}$, Nadine Mestre-Francés ${ }^{4}$, Jean-

6 Michel Verdier $^{4}$, Elke Zimmermann ${ }^{1}$

$9{ }^{1}$ Institute of Zoology, University of Veterinary Medicine Hannover, Bünteweg 17, 30559

10 Hannover, Germany

$11{ }^{2}$ Present address: Centre for Comparative and Evolutionary Psychology, King Henry

12 Building, King Henry 1st Street, Portsmouth, PO1 2DY, United Kingdom

$13{ }^{3}$ Small Animal Clinic, University of Veterinary Medicine Hannover, Bünteweg 4, 30559

14 Hannover, Germany

$15{ }^{4}$ Université Montpellier 2, Montpellier, France; Inserm U1198, Montpellier, France; EPHE,

16 Paris, France

20 Corresponding author:

21 Marko Dubicanac

$22 \quad$ Tel.: +495119538743

$23 \quad$ Fax.: +495118586

24 Email: markodubicanac@gmx.de 
26 Abstract

27

28 Objective: The aim of this study was to assess the practicability of common tonometers used

29 in veterinary medicine for rapid IOP screening, to calibrate IOP values gained by the

30 tonometers and to define a reference IOP value for the healthy eye in a new primate model

31 for aging research, the gray mouse lemur.

32 Studied animals \& Procedures: TonoVet ${ }^{\circledR}$ and the TonoPen ${ }^{\mathrm{TM}}$ measurements were

33 calibrated manometrically in healthy enucleated eyes of mouse lemurs euthanized for

34 veterinary reasons. For comparison of the practicability of both tonometers as a rapid IOP

35 assessment tool for living mouse lemurs, the IOP of 24 eyes of 12 hand-fixed animals (six

36 males and six females) was measured. To define a standard reference value for IOP in 258

37 healthy mouse lemurs, two of the largest colonies in the world were examined using the most

38 practicable tonometer.

39 Results: IOP measurements for the TonoVet ${ }^{\circledR}$ can be corrected by the formula: $y=0.981+$

$40 \quad(1.962 *$ TonoVet $\AA$ value $)$, for the TonoPen ${ }^{\mathrm{TM}}$ by $\mathrm{y}=5.38+\left(1.426^{*}\right.$ TonoPen $^{\mathrm{TM}}$ value $)$. The

41 calibrated IOP for a healthy mouse lemur eye is $20.3 \pm 2.85 \mathrm{mmHg}$. The TonoVet $\AA$ showed

42 advantages in practicability, e.g. small corneal contact area, short and painless corneal contact

43 and time. IOP measurements of healthy mouse lemur eyes were not affected by age, sex, eye

44 side or colony.

45 Conclusion: Tonometry using TonoVet ${ }^{\circledR}$ is the more practicable assessement tool for IOP

46 measurement of the tiny eyes of living mouse lemurs. Pathological deviations can be

47 identified based on the described reference value.

48

49 Key words: intraocular pressure, tonometer, reference value, mouse lemur, primate, aging 50 


\section{$51 \quad$ Introduction}

52 Mouse lemurs belong to the smallest living primates worldwide. (1) Due to this fact, their

53 maintenance and breeding is more cost-efficient than in larger primate species and they are

54 also not known for spreading zoonotic diseases which makes them an extraordinary primate

55 model for research. Additionally mouse lemurs have a life expectancy which is much shorter

56 than in other non-human primate aging models with about 8 years in the wild and up to 18.5

57 years in captivity. $(2,3)$ The genome of mouse lemurs has recently also been sequenced by

58 the Broad Institute (GenBank accession number ABDC00000000). Besides of the importance

59 of mouse lemurs for biomedical as well as aging research, (4-9) they are also important for

60 evolutionary research, based on their high and cryptic species diversity, their uneven

61 distribution and their flexible adaptations to their natural habitats. (10)

62 Mouse lemurs are nocturnal and have relative small absolute eye sizes with $9.4 \mathrm{~mm}$ in

63 diameter. $(11,12)$ Aged gray mouse lemurs were reported to suffer from different eye

64 diseases such as cataract, retinal atrophy and buphthalmia, an abnormal enlargement of the

65 eyeball. (13) Whether this malformation was due to glaucoma, which causes ocular

66 hypertension, still need to be clarified though. Because of the difficulty in handling non-

67 anesthetized animals, however, IOP was never studied in mouse lemurs before. Applanation

68 and rebound tonometry are commonly used in veterinary medicine to determine IOP in

69 domestic animals such as dogs, $(14,15)$ cats, $(16-18)$ and birds $(19,20)$ as well as in

70 laboratory animals such as rats, $(21,22)$ rabbits $(23)$ and macaques. $(24,25)$ Since factory

71 settings for TonoPen ${ }^{\mathrm{TM}}$ and TonoVet $\AA$ are only available for common species in the

72 veterinary clinics such as dogs, cats and horses, for uncommon species it is necessary to

73 calibrate measurements by manometry to get a true IOP (tIOP) before defining standard

74 reference IOP values for a given species. (see e.g. rabbits, (26) birds (20) and macaques. (25)) 
75 The TonoPen ${ }^{\mathrm{TM}}$ is an applanation tonometer often used for intraocular measurements in

76 veterinary medicine. $(14,16,21)$ IOP measurement gives an indirect assessment of the IOP

77 by using the Imbert-Fick law. (27) It measures the counter pressure that is necessary to flatten

78 a thin membrane surrounding a sphere filled with liquid. Its use in dogs and cats is easy and

79 fast but requires a local anaesthesia of the cornea.

80 The TonoVet ${ }^{\circledR}$ is a rebound tonometer based on a patented measurement system which uses

81 a small, disposable probe which is brought into contact with the cornea. $(17,18,20,24,28)$

82 The probe is rebounding with a determined speed, correlating to the IOP. The higher the IOP

83 is, the higher the speed of the return-bounce. Its use is easy and fast and requires no local

84 anaesthesia.

85 In this study we applied TonoPen ${ }^{\mathrm{TM}}$ and TonoVet ${ }^{\circledR}$ as rapid IOP assessment tools to the gray

86 mouse lemur, to

87 1. calibrate IOP measurements of the tonometers by manometry,

88 2. assess the practicability of the tonometers to measure the IOP of mouse lemurs' eyes

89 in-vivo to screen colonies,

903 . apply the most practicable technique for screening IOP in two of the world's largest

91 colonies, to investigate the effect of eye position, sex, colony and age on IOP and

92 establish a reference value for IOP.

93

94

95

96

97

98

99 
$100 \quad$ Methods

101

102 Animals and maintenance

103 Mouse lemurs (Microcebus murinus) tested in this study belonged to two licensed breeding

104 colonies housed at the Institute of Zoology at the University of Veterinary Medicine

105 Hannover (for details in housing conditions see; (29) Hannover breeding licence number

$10642500 / 1 \mathrm{H}$ ) and the University of Montpellier 2 (Agreement $\mathrm{N}^{\mathrm{br}} \neq \mathrm{C}-34-172-23$ ). Out of 349

107 investigated animals 258 animals, which showed no ocular pathologies, have been used for

108 analysis, 75 (38 females; 37 males) from Hannover and 183 (101 females; 82 males) from

109 Montpellier, ranging from 0.5 to 10 years. All animals were born in captivity. Since mouse

110 lemurs are nocturnal, the captive animals were maintained under artificial light conditions

111 with a reversed light cycle. Additionally, animals in Montpellier are maintained under an

112 accelerated photoperiodic regime. This means that the photoperiodically triggered

113 reproductive "year" lasted 8 instead of 12 months. It has been shown that these conditions

114 accelerate aging processes in gray mouse lemurs by the factor 1.5. (30-32)

115

116 Ophthalmologic investigation

117 Handling for ophthalmological examinations was similar to the weekly caretaker handling of

118 the animals resulting in reduced stress for the lemurs. All examinations were conducted at the

119 end of the sleeping period/beginning of the activity period to minimize disturbances of the

120 animal's activity. All procedures applied in this study were licenced by the respective

121 authorities (Hannover licence number, 33.9-42502-05-11A200, LAVES to Elke

122 Zimmermann; Montpellier licence number, 34-124 to Jean-Michel Verdier).

123 
124 Both eyes of a lemur were investigated with a slit-lamp bio-microscope (SL-14; Kowa,

125 Eickemeyer, Germany) and indirect ophthalmoscope (Omega 100; Heine, Ettenheim,

126 Germany) to determine potential eye pathologies with a possible effect on IOP or corneal

127 consistence. To get a view on the lens and retina, mydriatic eye-drops (Mydrum ${ }^{\circledR}$, Chauvin

128 ankerpharm $\mathrm{GmbH}$, Berlin, Germany) were used to widen the pupil.

130 1. Manometry

131 We determined the IOP value of an enucleated eye with the TonoVet ${ }^{\circledR}$ and TonoPen ${ }^{\circledR}$, 132 respectively, at manometrically defined IOP pressure steps (DD-890, ATP Messtechnik

$133 \mathrm{GmbH}$, Ettenheim, Germany). The used manometer was calibrated by the bureau of standards

134 in Hannover (Mess- und Eichwesen Niedersachsen Betriebsstelle Eichamt Hannover,

135 Goethestraße 44, 30169 Hannover). The pressure measured by the manometer in this setup

136 (including the pressure in the examined eye) will be labelled as the true IOP (tIOP). The

137 values in the more relevant sector for clinical use between $5 \mathrm{mmHg}$ and $50 \mathrm{mmHg}$ have been

138 taken in steps of $5 \mathrm{mmHg} \pm 0.1 \mathrm{mmHg}$. Between $50 \mathrm{mmHg}$ and $100 \mathrm{mmHg}$ measurements

139 were taken in steps of $10 \mathrm{mmHg} \pm 0.1 \mathrm{mmHg}$.

140 Eight healthy eyes of four animals euthanized for veterinary reasons (incurable pathologies)

141 were enucleated transconjunctivally immediately after euthanasia. These eyes were called

142 healthy since they were found inconspicuous and showed no signs of pathological disease

143 according to an ophthalmological investigation performed not more than 6 months before.

144 After enucleation, the eyes were stored in $0.9 \% \mathrm{NaCl}$ solution at $6^{\circ} \mathrm{C}$ for up to a maximum of

1454 hours before measurement. A small bowl of dough was adjusted to ensure the fixation of

146 the enucleated eye. The cannula (24 G, length 25 mm, B. Braun Melsungen AG, D-34209)

147 was inserted transsclerally into the vitreous and was not moved or reinserted while taking the

148 measurement. The pressure was constant and measured values showed no fluctuation. 
149 Minimal leakages were observed sporadically, but sealed by themselves with higher pressure.

150 A three-way stopcock was connected with the cannula, the manometer and a NaCL solution

151 reservoir via three silicon tubes. Pressure was adjusted by changing the height of the $\mathrm{NaCl}$

152 solution reservoir. The whole system was opened all the time to avoid fluctuations. (see Fig.

153 1) Once the manometer displayed a constant pressure, the pressure was measured using the

154 TonoVet ${ }^{\circledR}$ and TonoPen ${ }^{\mathrm{TM}}$. Each complete measurement by the TonoVet ${ }^{\circledR}$ represented the

155 mean of four single values, for the TonoPen ${ }^{\mathrm{TM}}$ the mean consists out of four to five single

156 values. The measurement was carried out until three complete measurements per eye were

157 successfully obtained.

158

159

160

161 The tonometers TonoPen ${ }^{\mathrm{TM}}$ and TonoVet ${ }^{\circledR}$ were used to measure IOP in the eyes of 12

162 young mouse lemurs (6 males, 6 females; aged between 2 and 3 years; Colony Hannover).

163 Both eyes of these mouse lemurs were inconspicuous and showed no signs of pathological

164 diseases according to an ophthalmological investigation performed one day before.

165 Measurements of the TonoVet ${ }^{\circledR}$ and TonoPen ${ }^{\mathrm{TM}}$ have been taken 24 hours after the

166 ophthalmological investigation to minimize influences of the mydriatic eye-drops on the IOP.

167 Each animal was investigated on both eyes until a successful measurement with the

168 respective tonometer has been achieved. The successful measurement is indicated by an

169 acoustical signal.

170

171

172

173 


\section{2.a Rebound tonometry (TonoVet®)}

175 Six single values of the IOP were taken per eye by the TonoVet ${ }^{\circledR}$ tonometer (TonoVet ${ }^{\circledR}$;

176 ICare, Finland Oy). The TonoVet ${ }^{\circledR}$ then automatically deleted the lowest and highest value

177 and calculated the mean out of the remaining four values. Only successfully completed

178 measurements displaying a mean on the TonoVet ${ }^{\circledR}$ were recorded. One successfully

179 completed measurement per animal was taken. For all 12 animals no anaesthesia and no

180 forced fixation of the eyelids were necessary (see Fig. 2).

181

182

\section{2.b Applanation tonometry (TonoPen $\left.{ }^{\mathrm{TM}}\right)$}

183 The TonoPen ${ }^{\mathrm{TM}}$ tonometer (TonoPen ${ }^{\mathrm{TM}}$; Reichert ${ }^{\circledR}$ Technologies, Eickemeyer, Germany)

184 was used to measure IOP of the same 12 animals as for the TonoVet ${ }^{\circledR}$. Before measurements

185 were taken, the eyes were locally anaesthetized with eye-drops (Proparakain-POS $® 0.5 \%$ ).

186 To prevent a reflective wink of the eyelids of an animal, the examiner had to fix the eyelids

187 with his fingers in open position (see Fig. 3). Between four and five single values per eye

188 were necessary for the TonoPen ${ }^{\mathrm{TM}}$ to calculate a mean. Only successfully completed

189 measurements displaying a mean on the TonoPen ${ }^{\mathrm{TM}}$ were recorded. One successfully

190 completed measurement per animal was taken.

191

192

193 To determine a reference value for the healthy mouse lemur eye, a large sample size is

194 required.

195241 animals in Montpellier and 108 animals in Hannover have been investigated. For the

196 determination of the IOP the TonoVet ${ }^{\circledR}$ was used. The animals were investigated at the end

197 of the sleeping/beginning of the activity period. For Montpellier the time for investigation

198 ranged from 09:00 a.m. - 03:00 p.m. (beginning of activity period at 12:00 a.m. for all 
199 animals), for Hannover from 09:00 a.m. - 05:00 p.m. (beginning of activity period at 10:00

200 a.m., 12:00 a.m. or 02:00 p.m. respectively, according to the room). After IOP measurement,

201 an ophthalmological investigation was performed for each animal as described in the

202 paragraph ophthalmologic investigation to select animals with healthy eyes for this study. 58

203 animals for Montpellier and 33 animals for Hannover showing eye malformations were

204 thereby excluded from further analysis.

205

206

207

\section{Data analysis}

208

209

1. Manometric calibration of the IOP measured by TonoVet ${ }^{\circledR}$ and TonoPen ${ }^{\mathrm{TM}}$ in enucleated eyes

211 For the manometric calibration of the TonoVet ${ }^{\circledR}$ and TonoPen ${ }^{\mathrm{TM}}$ IOP measurements, we

212 performed a regression analysis out of the eight means (= eight eyes) per step mmHg per 213 instrument.

214

2. Comparison of IOP between TonoPen ${ }^{\mathrm{TM}}$ and TonoVet ${ }^{\circledR}$

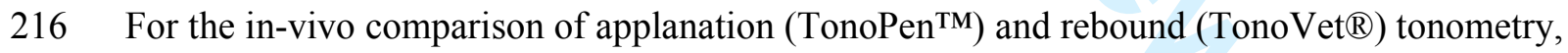

217 we calculated the mean, range, standard deviation and median IOP for each instrument out of

218 the measurements of the 24 eyes of the 12 animals. For the TonoVet ${ }^{\circledR}$ tonometer and the

219 TonoPen ${ }^{\mathrm{TM}}$ tonometer, we compared measured IOP values between left and right eyes using

220 the paired t-test and measured IOP values between sexes using the unpaired t-test since the

221 values followed a normal distribution. The IOP values obtained by the TonoPen ${ }^{\mathrm{TM}}$ and

222 TonoVet巴 were compared using the Wilcoxon-signed-rank test.

223 
3. Comparison of IOP across colonies

225 To assess the effect of sex and eye position, IOP values (using TonoVet ${ }^{\circledR} ; \mathrm{N}_{\text {totalanimals }}=258$,

$226 \mathrm{n}_{\text {totaleyes }}=516$; Hannover, $\mathrm{N}=75$; Montpellier, $\mathrm{N}=183$ ) obtained for each eye and animal per

227 colony were compared between the left and right eye and between sexes using the Wilcoxon-

228 signed-rank test and Mann-Whitney-U test, respectively.

229 If findings within colonies did not reveal a significant effect of eye position or sex, we used

230 the median value of an animal per colony for further statistical analysis. To explore the effect

231 of colony, we compared IOP values between colonies using the Mann-Whitney-U test.

232 The effect of age on IOP was analysed using a Spearman-Rank correlation. For the colony of

233 Montpellier, the cycle age was multiplied by the factor 1.5 to calculate the chronological age

234 in years. To define the reference IOP value for a healthy mouse lemur eye, we calculated the

235 mean, range, standard deviation and median of the IOP of the healthy eye of both colonies.

236

237

238

239

240

241

242

243

244

245

246

247

248 
249

250

251

252

253

254

255

256

257

258

259

260

261

262

263

264

265

266

267

268

269

270

271

272

\section{Results}

1. In vitro calibration of the rebound (TonoVet $\left.{ }^{\circledR}\right)$ and applanation (TonoPen ${ }^{\mathrm{TM}}$ ) tonometry

We found a linear correlation between either the rebound tonometry and direct manometry or applanation tonometry and direct manometry (see Fig. $4 ; \mathrm{n}=8$ eyes; $\mathrm{N}=4$ mouse lemurs).

The regression analysis showed consistent linear underestimation of IOP by the TonoVet ${ }^{\circledR}$ and TonoPen ${ }^{\mathrm{TM}}$. From $15 \mathrm{mmHg}$ up to $100 \mathrm{mmHg}$, the regression analysis showed that the measured IOP $(\mathrm{mIOP})$ for TonoVet ${ }^{\circledR}\left(\mathrm{F}=28263.232, \mathrm{r}^{2}=1\right.$, regression analysis, $\left.\mathrm{p}<0.001\right)$ can be corrected by using the function tIOP $=0.981+(1.962 * \mathrm{mIOP})$ and for TonoPen ${ }^{\mathrm{TM}}(\mathrm{F}$ $=3497.514, \mathrm{r}^{2}=0.997$, regression analysis, $\left.\mathrm{p}<0.001\right)$ by using the function $\mathrm{tIOP}=5.38+$ $(1.426 * \mathrm{mIOP})$. In both tonometers it was not possible to obtain values below $15 \mathrm{mmHg}$. From $15 \mathrm{mmHg}$ up to $100 \mathrm{mmHg}$ the TonoVet ${ }^{\circledR}$ constantly underestimated the tIOP by half. While the TonoPen ${ }^{\mathrm{TM}}$ almost measured the same values at $20 \mathrm{mmHg}$ as the TonoVet ${ }^{\circledR}$, the measured values start slightly to increase compared to the TonoVet ${ }^{\circledR}$ reaching around $66 \%$ of the tIOP at $100 \mathrm{mmHg}$.

\section{In-vivo IOP measurements with TonoPen ${ }^{\mathrm{TM}}$ and TonoVet ${ }^{\circledR}$}

A comparison of IOP values between the left and right eye for each instrument showed no significant difference between eye side $\left(\right.$ TonoVet ${ }^{\circledR}$, paired $\mathrm{t}$-test, $\mathrm{N}=12, \mathrm{t}=-0.538, \mathrm{p}=$ 0.601; TonoPen ${ }^{\mathrm{TM}}$, paired t-test, $\left.\mathrm{N}=12, \mathrm{t}=-0.794, \mathrm{p}=0.444\right)$. 
273 No difference between sexes was found for IOP neither for the TonoVet ${ }^{\circledR}$ (unpaired t-test,

$274 \mathrm{~N}_{\text {total }}=24, \mathrm{~N}_{\text {males }}=\mathrm{N}_{\text {females }}=6, \mathrm{t}=-0.130, \mathrm{p}=0.292$ ) nor for the TonoPen ${ }^{\mathrm{TM}}$ (unpaired t-test,

$275 \mathrm{~N}_{\text {total }}=24, \mathrm{~N}_{\text {males }}=\mathrm{N}_{\text {females }}=6, \mathrm{t}=-0.340, \mathrm{p}=0.198$ ). Thus, we have not differentiated between

276 sexes in all further analyses.

277 The mean IOP for the TonoVet ${ }^{\circledR}$ tonometer was $9.21 \pm 1.53 \mathrm{mmHg}$, the median was 9.0

$278 \mathrm{mmHg}$ and the range $6-12 \mathrm{mmHg}$, the tIOP was $19.03 \pm 2.24 \mathrm{mmHg}$.

279 For the TonoPen ${ }^{\mathrm{TM}}$ tonometer the mean was $23.83 \pm 5.89 \mathrm{mmHg}$, the median $24.5 \mathrm{mmHg}$

280 and the range $14-38 \mathrm{mmHg}$ with a tIOP of $39.36 \pm 5.1 \mathrm{mmHg}$. (see Tab. 1)

281 IOP values measured by the TonoVet ${ }^{\circledR}$ and the TonoPen ${ }^{\mathrm{TM}}$ differed significantly (Wilcoxon-

282 test, $\mathrm{N}=24, \mathrm{~T}=0.00, \mathrm{n}=24, \mathrm{p}=<0.001$ ). The comparison of measured values between

283 instruments showed a higher estimation of the average IOP for the TonoPen ${ }^{\mathrm{TM}}$. The average

284 value for the TonoPen ${ }^{\mathrm{TM}}$ is more than twice as high as the average value estimated by the

285 TonoVet $\AA$. Measurements with the TonoPen ${ }^{\mathrm{TM}}$ in the same animal for the left and right eye

286 show high variability, while the values obtained with the TonoVet ${ }^{\circledR}$ are much more

287 consistent e.g. Peanut (TonoPen ${ }^{\mathrm{TM}}$ left eye $38 \mathrm{mmHg}$, right eye $16 \mathrm{mmHg}$; TonoVet ${ }^{\circledR}$ left

288 eye $10 \mathrm{mmHg}$, right eye $9 \mathrm{mmHg}$ ). (see Fig. 5)

289

290 Several problems occurred in the application of the TonoPen ${ }^{\mathrm{TM}}$ in the examiner-animal

291 context. The tip of the TonoPen ${ }^{\mathrm{TM}}$ was large in comparison to the small eyes of the mouse

292 lemurs causing reflective winks of the animal because of contact to the animals' eyelashes. It

293 was not possible to fixate the animals' eye-lids without causing indirect pressure on the eye-

294 bulb. Besides, the examiner had to protect himself against bites since the hand which was

295 fixating the animals' eye-lids was hazardously close to the animals' mouth and sharp teeth.

296 The time that was necessary to complete one successful measurement per animal varied

297 between 5 and 10 minutes (without waiting time for the applied anaesthetizing eye-drops). 
299 When using the TonoVet ${ }^{\circledR}$ for IOP measurement, the animals showed no visible reaction

300 when the probe touched the animals' cornea, furthermore almost no reflective wink was

301 visible. Since no forced fixation of the animals' eye-lids was necessary, bites never occurred.

302 The investigation lasted on average only 30 seconds.

3. Comparison of IOP between two mouse lemur colonies and the definition of a reference IOP value for the gray mouse lemur

Both colonies have been investigated using the TonoVet ${ }^{\circledR}$. A comparison between measured IOP values in the left and right eye for each colony showed no significant differences (Hannover, Wilcoxon-test, $\mathrm{N}=75, \mathrm{~T}=22.05, \mathrm{n}=47, \mathrm{p}=0.361$; Montpellier, Wilcoxon-test,

$311 \mathrm{~N}=183, \mathrm{~T}=55.27, \mathrm{n}=113, \mathrm{p}=0.336)$.

312 No difference between sexes was found for IOP (Hannover, Mann-Whitney-test, $\mathrm{N}_{\text {total }}=150$,

$313 \mathrm{~N}_{\text {males }}=37$ eye-pairs, $\mathrm{N}_{\text {females }}=38$ eye-pairs, $\mathrm{U}=-1.314, \mathrm{p}=0.189$; Montpellier, Mann-

314 Whitney-test, $\mathrm{N}_{\text {total }}=366, \mathrm{~N}_{\text {males }}=82$ eye-pairs, $\mathrm{N}_{\text {females }}=101$ eye-pairs, $\mathrm{U}=-1.552, \mathrm{p}=$

315 0.121). Thus, sexes were not further differentiated in further analyses.

316 The comparison of IOP values between both colonies showed no significant difference

317 (Mann-Whitney-test, $\mathrm{N}_{\text {total }}=516, \mathrm{~N}_{\text {Hannover }}=75$ eye-pairs, $\mathrm{N}_{\text {Montpellier }}=183$ eye-pairs, $\mathrm{U}=$ -

$3180.230, \mathrm{p}=0.818$ ). Based on that, we did not further differentiate between colonies for 319 subsequent analysis.

320 The effect of age on IOP was assessed by a Spearman-Rank correlation. No significant 321 correlation between chronological age and IOP was revealed $\left(\mathrm{p}=0.418, \mathrm{r}_{\mathrm{s}}=-0.036, \mathrm{~N}=516\right.$, 322 see Fig. 6). Thus, age has not affected IOP in the healthy eye for the investigated age-span. 
323 Based on that a reference value for IOP measured with the TonoVet ${ }^{\circledR}$ was calculated with a

324 mean of $9.87 \pm 1.56 \mathrm{mmHg}$, a median of $10 \mathrm{mmHg}$ and a range of $5-15 \mathrm{mmHg}$. Using the

325 regression function the calculated mean for healthy mouse lemur eyes is tIOP $=20.3 \pm 2.85$

$326 \mathrm{mmHg}$.

327

328

329

330

331

332

333

334

335

336

337

338

339

340

341

342

343

344

345

346

347 


\section{Discussion}

349

350 This is the first study measuring the IOP of mouse lemurs. Our findings suggest that the

351 TonoVet ${ }^{\circledR}$ is the most suitable tool (compared to the TonoPen ${ }^{\mathrm{TM}}$ ) for rapid IOP screening of

352 the tiny eyes of this smallest bodied primate. Results showed that IOP in the clinically

353 healthy eye is not affected by age, sex, eye side (left or right). Thus, a reference value for IOP

354 could be defined based on a large sample-size of more than 250 individuals for this novel

355 primate model for aging research.

356

357 Calibration of IOP using manometry

358 Every tonometer has to be calibrated for each species specifically due to the fact of different

359 corneal attributes, especially corneal thickness, to get the tIOP values. $(33,34)$ IOP

360 measurements using eyes persisting in the eye socket in ex-vivo as well as enucleated eyes

361 revealed no significant differences between these procedures. (35) Manometric in-vivo

362 measurement of IOP is, however, known to potentially cause damage at intraocular structures

363 and pain, thus for ethical reasons we decided to base our manometric investigation on

364 enucleated eyes of animals which died for natural reasons or were euthanized due to

365 incurable diseases which had no impact on IOP.

366 Our manometric calibration for the TonoVet ${ }^{\circledR}$ and TonoPen ${ }^{\mathrm{TM}}$ showed a consequent linear

367 underestimation of the tIOP for both instruments which can be corrected by the established

368 regression functions. For a fast clinical interpretation of the measurements displayed on the

369 TonoVet ${ }^{\circledR}$ the values can be multiplied by 2 . For the TonoPen ${ }^{\mathrm{TM}}$ a similar but not as easy to

370 use formula is: $\mathrm{tIOP}=(1.5 *$ measured value $)+5$.

371 A comparable underestimation of the IOP measured by the TonoVet ${ }^{\circledR}$ and TonoPen ${ }^{\mathrm{TM}}$ was

372 reported for dog eyes. (15) This underestimation was explained by corneal specification 
373 especially corneal thickness, calibration-standards and use by different examiners. For our

374 study, the same examiner performed the measurements so that the effect of the examiner on

375 the measured IOP values was minimized whereas both corneal specification and different

376 calibration standards between TonoVet ${ }^{\circledR}$ and TonoPen ${ }^{\mathrm{TM}}$ are likely to explain the

377 underestimation of IOP values. In humans a significant effect on IOP measurements caused

378 by different thickness in different corneal areas using the rebound tonometry has already been

379 shown: higher values were determined when corneal thickness was higher. $(33,34)$ Our

380 measurements were taken at the center of the cornea to minimize this effect. We expect that

381 central corneal thickness in mouse lemurs is relatively thin, which would explain the linear

382 underestimation. Further investigations on corneal thickness of mouse lemurs e.g. with an

383 ultrasound pachymeter are necessary to investigate this in more detail.

385 Practicability of TonoPen ${ }^{\mathrm{TM}}$ or TonoVet ${ }^{\circledR}$ to screen the IOP of mouse lemur eyes

386 The practical value of a tonometer is as important as the calibration. Thus, which of the

387 commonly used tonometers in veterinary science, TonoPen ${ }^{\mathrm{TM}}$ or TonoVet $\AA$, is the most

388 suitable tool to screen tiny eyes of a large number of mouse lemurs in colonies on a regular

389 basis? The eyes of the gray mouse lemur have only a diameter of $9.4 \mathrm{~mm}$. (11) Thus, a

390 previous ophthalmological study in the gray mouse lemur had difficulties in using

391 applanation tonometry in non-anesthetized animals. (13) We applied both the TonoPen ${ }^{\mathrm{TM}}$ and

392 the TonoVet ${ }^{\circledR}$ for a subgroup of non-anesthetized animals to assess the practicability of these

393 instruments. We showed that both tonometers can be applied, but that there are huge

394 differences in practicability and ethical justifiability. The investigation with the TonoPen ${ }^{\mathrm{TM}}$

395 required a much longer time (up to 10 minutes) to assess the IOP of an animal compared to

396 TonoVet ${ }^{\circledR}$ (up to 30 seconds). The most time consuming issue emerged by the high number

397 of failed IOP measurements (indicated by an alarm-signal of the TonoPen ${ }^{\mathrm{TM}}$ ). The failure in 
measurement was due to the fact that the veterinarian had to pay attention to exerted pressure,

399 contact-area and animal position while measuring the IOP. In contrast, unsuccessful

400 measurements (indicated by an alarm-signal) were quite rare for the TonoVet ${ }^{\circledR}$. Furthermore,

401 the small eye-bulbs of the mouse lemurs make it necessary to fixate the eye-lids manually

402 and eventually causing pressure on the eye-bulb whereas no fixations of the animal's eye-lids

403 were necessary for the TonoVet ${ }^{\circledR}$. The animal itself must be fixated much stronger when

404 using the TonoPen ${ }^{\mathrm{TM}}$ causing systemical hypertension and consecutively higher IOP.

405 Consequently, our experience using the TonoPen ${ }^{\mathrm{TM}}$ supports Beltran et al. (13) that the use of

406 this instrument to measure IOP in the tiny eyes of mouse lemurs is problematic. The

407 extensive manipulation which is necessary prevents the determination of physiological

408 expected IOP values. Usually physiological IOP ranges from $15-23 \mathrm{mmHg}$ e.g. in humans,

409 (36) dogs, (14) cats, (18) horses, (28) rabbits, (23) rats (21) and macaques. (37) (see Tab. 2)

410 Therefore non-physiologically high IOP as measured with the TonoPen ${ }^{\mathrm{TM}}$ in mouse lemurs

$411 \quad(\mathrm{tIOP}=39.36 \pm 5.1)$ may be the result of stress, high systemic blood pressure and unintended

412 pressure on the bulbus questioning the ethical justifiability of this method.

413 Other positive effects of the TonoVet ${ }^{\circledR}$ were that IOP of non-anesthetized animals can be

414 measured rapidly and without any visible harm for the measured animal. Furthermore a

415 veterinarian can standardize the measurement quickly and get fast routinisation. The

416 TonoVet巴 showed satisfying results concerning reproducibility with a relatively small

417 variation comparable to those of other studies using larger mammals such as rhesus macaques

418 (25) or rabbits. (26) All in all, based on these findings we recommend the TonoVet ${ }^{\circledR}$ as a

419 suitable IOP assessment tool for rapid screening of the eyes in non-anaesthetized mouse

420 lemurs.

421

422 
423 Definition of a reference IOP for the healthy gray mouse lemur eye

424 A reliable mean for IOP in mouse lemurs requires a large sample-size. To enlarge our

425 sample-size we have analyzed if eye side (left or right), sex or age had any influence on IOP

426 in mouse lemurs. Our study showed no significant differences between eye side and sex and

427 no statistically significant correlation between age and IOP. The slight decrease of IOP

428 between the age of 0.5 and 10 years was even smaller than the value of the determined

429 standard deviation. Animals of ten years and older were excluded due to diagnosed

430 pathologies.

431 Our screening analysis of the two colonies, Hannover and Montpellier, included 258 animals

432 with 516 healthy eyes in total and showed a tIOP of $20.3 \pm 2.85 \mathrm{mmHg}$. This value matches

433 quite well to the IOP range of $15-23 \mathrm{mmHg}$ reported from humans (36) and mammals of

434 veterinary and biomedical importance (see Tab. 2) such as dogs, (14) cats, (18) horses, (28)

435 rabbits, (23) rats (21) and macaques. (37) Since these mammals differ largely in size, activity

436 and phylogeny, IOP seems to be independent from these factors.

437 Circadian rhythm is also described to affect IOP, e.g. in cats, rabbits and Tibetan monkey.

438 (23),(38),(39) To minimize this effect, we always determined IOP at the beginning of the

439 animal's activity period.

440 Our study showed no correlation between age and IOP in the healthy mouse lemur eye

441 comparable to e.g. Tibetan monkeys. (39) Age-effects on IOP in animals and humans are

442 ambiguous. Whereas investigations performed in rhesus monkeys and dogs showed a

443 decrease in IOP with age (37),(14) studies in humans revealed both an increase and a

444 decrease depending on the tested populations. (40),(36),(41) High blood pressure, obesity and

445 other vascular deficiencies were discussed as explanations. (42-44) Consequently we

446 postulate that physiological status and vascular conditions were healthy in our studied mouse

447 lemur population. 
1

2

3

4

5

6

7

8

9

10

448 It has to be taken into account that for our study we considered only ophthalmological

449 inconspicuous animals. Pathologies influencing the state of health of the eye and leading to

450 glaucoma or higher intraocular pressure have to be considered in follow-up studies.

451

\section{Conclusion}

453 To conclude, we demonstrated the practicability, usefulness and reliability of the TonoVet ${ }^{\circledR}$

454 as a powerful tool for screening IOP in mouse lemurs, a novel primate model for human

455 aging research. Average IOP of healthy mouse lemur eyes is not affected by eye side, sex and

456 colony and does not correlate with age. Furthermore, the value of IOP of mouse lemurs

457 coincides with those of other mammals. For future studies using this smallest-bodied primate 458 aging model, our findings are an important foundation to disentangle peripheral from central 459 pathologies.

\section{Software for statistical analysis}

464 The statistical analysis was performed using SPSS 22.0 for Windows. Significance level was 465 set at $\mathrm{P}=0.05$.

468 List of Abbreviations

469 IOP: Intraocular pressure; tIOP: true intraocular pressure; mIOP: measured intraocular 470 pressure 
472 Competing interests

473 The authors declare that they have no competing interests.

474

475 Authors' contributions

$476 \mathrm{MD}, \mathrm{MJ}, \mathrm{EZ}, \mathrm{IN}$, JS have conceived, coordinated and designed the study. Manometrical data

477 was acquired by MD. Data from the screening of both colonies was acquired by MD and MJ.

478 Statistical analysis was conducted by MD. All authors contributed in drafting, reading and

479 approving the final manuscript.

480

481 Acknowledgements

482 We are grateful to all caretakers and assistants who helped collecting data: Lisabelle Früh, 483 Iris Grages, Johanna Samtlebe, Sönke von den Berg, Elisabeth Engelke, Jennifer Brunke, 484 Kathrin Röper, Annette Klaus, Eva Schuster, May Hokan, Sabrina Linn, Sylvie Rouland and 485 Joël Cuoq.

486 This study was partly supported by the European Community's 7th Framework Programme 487 (FP7/2007-2013) under grant agreement no. 278486 acronym “DEVELAGE” (EZ, JMV). 488 489 490 491 492 493 494 495 496 
497 REFERENCES

498 1. Mittermeier R, Louis JE, Richardson M, et al. Lemurs of Madagascar. 3rd edition.

499 Conservation International, 2010.

500 2. Zimmermann E, Radespiel U. Handbook of Paleoanthropology, Primate Evolution

501 and Human Origins. Springer Verlag, NY, 2007.

502 3. Weigl R, Jones M. Longevity of mammals in captivity: from the living collections of

503 the world: a list of mammalian longevity in captivity. Schweizerbart, Stuttgart, 2005.

504 4. Verdier J, Acquatella I, Lautier C, et al. Lessons from the analysis of nonhuman

505 primates for understanding human aging and neurodegenerative diseases. Frontiers in

$506 \quad$ Neuroscience. 2015.

507 5. Austad SN, Fischer KE. The development of small primate models for aging research.

508 ILAR journal / National Research Council, Institute of Laboratory Animal Resources. 2011;

$509 \quad 52(1): 78-88$.

510 6. Mestre-Frances N, Keller E, Calenda A, et al. Immunohistochemical analysis of

511 cerebral cortical and vascular lesions in the primate Microcebus murinus reveal distinct

512 amyloid beta1-42 and beta1-40 immunoreactivity profiles. Neurobiology of disease. 2000;

513 7(1): 1-8.

514 7. Bons N, Jallageas V, Silhol S, et al. Immunocytochemical characterization of Tau

515 proteins during cerebral aging of the lemurian primate Microcebus murinus. Comptes rendus

516 de l'Academie des sciences Serie III, Sciences de la vie. 1995; 318(7): 741-747.

517 8. Dhenain M, Michot JL, Privat N, et al. MRI description of cerebral atrophy in mouse 518 lemur primates. Neurobiology of aging. 2000; 21(1): 81-88.

519 9. Kraska A, Dorieux O, Picq JL, et al. Age-associated cerebral atrophy in mouse lemur 520 primates. Neurobiology of aging. 2011; 32(5): 894-906. 
521 10. Zimmermann E, Radespiel U. Species concepts, diversity, and evolution in primates:

522 lessons to be learned from mouse lemurs. Evolutionary anthropology. 2014; 23(1): 11-14.

523 11. Kirk EC. Comparative morphology of the eye in primates. The anatomical record

524 Part A, Discoveries in molecular, cellular, and evolutionary biology. 2004; 281(1): 1095-

5251103.

526 12. Ross CF, Kirk EC. Evolution of eye size and shape in primates. Journal of human 527 evolution. 2007; 52(3): 294-313.

528 13. Beltran WA, Vanore M, Ollivet F, et al. Ocular findings in two colonies of gray

529 mouse lemurs (Microcebus murinus). Veterinary ophthalmology. 2007; 10(1): 43-49.

530 14. Gelatt KN, MacKay EO. Distribution of intraocular pressure in dogs. Veterinary

531 ophthalmology. 1998; 1(2-3): 109-114.

532 15. Gorig C, Coenen RT, Stades FC, et al. Comparison of the use of new handheld

533 tonometers and established applanation tonometers in dogs. American journal of veterinary

534 research. 2006; 67(1): 134-144.

535 16. Miller PE, Pickett JP, Majors LJ, et al. Evaluation of two applanation tonometers in

536 cats. American journal of veterinary research. 1991; 52(11): 1917-1921.

537 17. McLellan GJ, Kemmerling JP, Kiland JA. Validation of the TonoVet(R) rebound

538 tonometer in normal and glaucomatous cats. Veterinary ophthalmology. 2013; 16(2): 111-

539118.

540 18. Rusanen E, Florin M, Hassig M, et al. Evaluation of a rebound tonometer (Tonovet)

541 in clinically normal cat eyes. Veterinary ophthalmology. 2010; 13(1): 31-36.

542 19. Willis AM, Wilkie DA. AVIAN ophthalmology, part 1: anatomy, examination, and

543 diagnostic techniques. Journal of Avian Medicine and Surgery. 1999; 13(3): 160-166.

544 20. Reuter A, Muller K, Arndt G, et al. Accuracy and reproducibility of the TonoVet

545 rebound tonometer in birds of prey. Veterinary ophthalmology. 2010; 13 Suppl: 80-85. 
546 21. Mermoud A, Baerveldt G, Minckler DS, et al. Intraocular pressure in Lewis rats.

547 Investigative ophthalmology \& visual science. 1994; 35(5): 2455-2460.

548 22. Goldblum D, Kontiola AI, Mittag T, et al. Non-invasive determination of intraocular

549 pressure in the rat eye. Comparison of an electronic tonometer (TonoPen), and a rebound

550 (impact probe) tonometer. Graefe's archive for clinical and experimental ophthalmology =

551 Albrecht von Graefes Archiv fur klinische und experimentelle Ophthalmologie. 2002;

$552 \quad 240(11): 942-946$.

553 23. Pereira FQ, Bercht BS, Soares MG, et al. Comparison of a rebound and an

554 applanation tonometer for measuring intraocular pressure in normal rabbits. Veterinary

555 ophthalmology. 2011; 14(5): 321-326.

556 24. Elsmo EJ, Kiland JA, Kaufman PL, et al. Evaluation of rebound tonometry in non-

557 human primates. Experimental eye research. 2011; 92(4): 268-273.

558 25. Yu W, Cao G, Qiu J, et al. Evaluation of monkey intraocular pressure by rebound

559 tonometer. Molecular vision. 2009; 15: 2196-2201.

560 26. Kalesnykas G, Uusitalo H. Comparison of simultaneous readings of intraocular

561 pressure in rabbits using Perkins handheld, Tono-Pen XL, and TonoVet tonometers. Graefe's

562 archive for clinical and experimental ophthalmology = Albrecht von Graefes Archiv fur

563 klinische und experimentelle Ophthalmologie. 2007; 245(5): 761-762.

564 27. Fick A. Über die Messung des Druckes im Auge. Archive für die gesamte Physiologie

565 des Menschen und der Tiere 1888; 42(1): 86-90.

566 28. Knollinger AM, La Croix NC, Barrett PM, et al. Evaluation of a rebound tonometer

567 for measuring intraocular pressure in dogs and horses. Journal of the American Veterinary

568 Medical Association. 2005; 227(2): 244-248. 
569 29. Wrogemann D, Radespiel U, Zimmermann E. Comparison of reproductive

570 characteristics and changes in body weight between captive populations of rufous and gray

571 mouse lemurs. International Journal of Primatology. 2001; 22(1): 91-108.

572 30. Dubicanac M, Joly M, Strüve J, et al. Ocular Pathologies In Aging Gray Mouse

573 Lemurs (Microcebus Murinus) (abstract). 25th Conference of the International

574 Primatological Society, 2014.

575 31. Perret M. Change in photoperiodic cycle affects life span in a prosimian primate

576 (Microcebus murinus). Journal of biological rhythms. 1997; 12(2): 136-145.

577 32. Languille $\mathrm{S}$, Blanc S, Blin $\mathrm{O}$, et al. The grey mouse lemur: a non-human primate

578 model for ageing studies. Ageing research reviews. 2012; 11(1): 150-162.

579 33. Jorge JM, Gonzalez-Meijome JM, Queiros A, et al. Correlations between corneal

580 biomechanical properties measured with the ocular response analyzer and ICare rebound

581 tonometry. Journal of glaucoma. 2008; 17(6): 442-448.

582 34. Martinez-de-la-Casa JM, Garcia-Feijoo J, Vico E, et al. Effect of corneal thickness on

583 dynamic contour, rebound, and goldmann tonometry. Ophthalmology. 2006; 113(12): 2156-

5842162.

585 35. Güse J. Messung das Augeninnendrucks beim Pferd mit dem Tonovet ${ }^{\circledR}$ - Präzision,

586 Reliabilität und Anwendbarkeit. Hanover, Germany: University of Veterinary Medicine;

5872008.

588 36. Shiose Y. Intraocular pressure: new perspectives. Survey of ophthalmology. 1990;

589 34(6): 413-435.

590 37. Bito LZ, Merritt SQ, DeRousseau CJ. Intraocular pressure of rhesus monkey (Macaca

591 mulatta). I. An initial survey of two free-breeding colonies. Investigative ophthalmology \&

592 visual science. 1979; 18(8): 785-793. 
593 38. Del Sole MJ, Sande PH, Bernades JM, et al. Circadian rhythm of intraocular pressure 594 in cats. Veterinary ophthalmology. 2007; 10(3): 155-161.

595 39. Liu G, Zeng T, Yu W, et al. Characterization of intraocular pressure responses of the 596 Tibetan monkey (Macaca thibetana). Molecular vision. 2011; 17: 1405-1413.

597 40. Colton T, Ederer F. The distribution of intraocular pressures in the general population. 598 Survey of ophthalmology. 1980; 25(3): 123-129.

599 41. Shiose Y. The aging effect on intraocular pressure in an apparently normal population. 600 Archives of ophthalmology. 1984; 102(6): 883-887.

601 42. Bulpitt CJ, Hodes C, Everitt MG. Intraocular pressure and systemic blood pressure in 602 the elderly. The British journal of ophthalmology. 1975; 59(12): 717-720.

603 43. Klein BE, Klein R, Knudtson MD. Intraocular pressure and systemic blood pressure:

604 longitudinal perspective: the Beaver Dam Eye Study. The British journal of ophthalmology. $605 \quad 2005 ; 89(3): 284-287$.

606 44. Mori K, Ando F, Nomura H, et al. Relationship between intraocular pressure and 607 obesity in Japan. International journal of epidemiology. 2000; 29(4): 661-666.

608

609

610

611

612

613

614

615

616

617 
618 Figure 1. Setup of the manometrical investigation.

619

620

Figure 2. Investigation of a 2 year old mouse lemur with the TonoVet®.

621

622

Figure 3. Investigation of a 2 year old mouse lemur with the TonoPen ${ }^{\mathrm{TM}}$

623

624 Figure 4. Values measured with the TonoVet ${ }^{\circledR}$ and TonoPen ${ }^{\mathrm{TM}}$ under manometrical

625 control. Manometrically determined IOP for the eight eyes of four animals are represented 626 on the X-axis. TonoVet $\AA$ and TonoPen ${ }^{\mathrm{TM}}$ values are represented on the $\mathrm{y}$-axis. Each dot 627 represents the mean from three measurements per step/per eye. The dashed line represents the 628 regression line for the TonoVet ${ }^{\circledR}\left(F=28263.232, r^{2}=1\right.$, regression analysis, $\left.\mathrm{p}<0.001\right)$ and $629 \operatorname{TonoPen}^{\mathrm{TM}}\left(\mathrm{F}=3497.514, \mathrm{r}^{2}=0.997\right.$, regression analysis, $\left.\mathrm{p}<0.001\right)$ measurements.

630

631 Figure 5. Comparison of the in-vivo measured IOP for the TonoVet ${ }^{\circledR}$ and TonoPen ${ }^{\mathrm{TM}}$ in

63212 animals. The results show high variation in measurements for the TonoPen ${ }^{\mathrm{TM}}$ and much 633 more consistent values for the TonoVet ${ }^{\circledR}$. E.g. Peanut (TonoPen ${ }^{\mathrm{TM}}$ left eye $38 \mathrm{mmHg}$, right 634 eye $16 \mathrm{mmHg}$; TonoVet巴 left eye $10 \mathrm{mmHg}$, right eye $9 \mathrm{mmHg}$ ). For exact values (see Tab. $6351)$

Figure 6. Relation between tIOP values and age in healthy mouse lemur eyes. This 638 scatterplot shows the tIOP values for all measured healthy animals from Hannover and 639 Montpellier $(\mathrm{N}=258)$ on the $y$-axis in relation to age on the $\mathrm{x}$-axis. The decrease in IOP is 640 statistically not significant $\left(\mathrm{p}=0.077, \mathrm{r}_{\mathrm{s}}=-0.110\right)$. 
Table 1. Overview of intraocular pressure (IOP) values in 12 animals for TonoVet ${ }^{\circledR}$ and TonoPen ${ }^{\mathrm{TM}}$.

The median, range, mean and standard deviation have been calculated for each instrument using the median from each animal's right and left eye.

\begin{tabular}{|c|c|c|c|c|}
\hline \multirow[b]{2}{*}{ Animal name } & \multicolumn{2}{|c|}{$\begin{array}{l}\text { TonoVet@ IOP results } \\
(\mathrm{mmHg})\end{array}$} & \multicolumn{2}{|c|}{$\begin{array}{l}\text { TonoPen }{ }^{\mathrm{TM}} \text { IOP results in } \\
\mathrm{mmHg}\end{array}$} \\
\hline & Right eye & Left eye & Right eye & Left eye \\
\hline Pixel $\hat{o}(2$ years $)$ & 10 & 9 & 27 & 22 \\
\hline Quilla $+(3$ years $)$ & 11 & 11 & 21 & 29 \\
\hline Quinn $\widehat{\partial}^{\wedge}(3$ years $)$ & 9 & 10 & 18 & 25 \\
\hline Quelle ${ }_{+}(3$ years $)$ & 9 & 8 & 24 & 28 \\
\hline Quirl $\delta^{\lambda}(3$ years $)$ & 8 & 7 & 17 & 16 \\
\hline Pippi $+(2$ years $)$ & 10 & 6 & 22 & 14 \\
\hline Paloma $+(2$ years $)$ & 10 & 9 & 23 & 25 \\
\hline Peanut $\delta^{\wedge}(2$ years $)$ & 9 & 10 & 16 & 38 \\
\hline Quentin ${ }^{\lambda}(3$ years $)$ & 11 & 11 & 28 & 18 \\
\hline Queenie $q(3$ years $)$ & 8 & 12 & 19 & 33 \\
\hline Pandora $+(2$ years $)$ & 7 & 10 & 27 & 26 \\
\hline Phil $\widehat{\partial}(2$ years $)$ & 7 & 9 & 31 & 25 \\
\hline Median (mmHg) & & 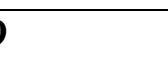 & & \\
\hline Range (mmHg) & & 12 & & \\
\hline Mean \pm SD $(\mathrm{mmHg})$ & & 1.53 & & $=5.89$ \\
\hline
\end{tabular}


1 Table 2. Variation of calibrated intraocular pressure (IOP) values in different species 2

\begin{tabular}{|l|c|l|l|}
\hline Species & Reference & or range & Standard \\
deviation
\end{tabular}
3 